\title{
Effect of Lavender Aromatherapy on Sleep Quality and Physiological Indicators in Patients after CABG Surgery: A Clinical Trial Study
}

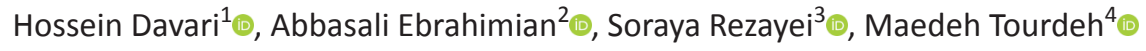

\begin{abstract}
Background: Sleep disorders occur in the first days after heart surgery. One of the major causes of sleep disorders after coronary artery bypass graft (CABG) is subsequent changes in physiological indicators, such as systolic blood pressure (BP), respiratory rate (RR), saturation of oxygen $\left(\mathrm{O}_{2}\right)$, and heart rate (RR). This study is aimed to determine the effect of lavender aromatherapy on patients' sleep quality and physiological indicators after CABG.

Materials and methods: This study was a randomized clinical trial. Patients after CABG surgery were randomly allocated into the lavender and distilled water groups. Patients in the intervention group inhaled lavender while those in the control group inhaled distilled water for 10 hours. Sleep quality and physiological postoperative data were collected for 3 days. Data were analyzed using repeated measurement test, sample t-test, and Chi-square test.

Results: Repeated measurement test showed no significant difference between the lavender and distilled water groups in terms of systolic BP, $\mathrm{RR}, \mathrm{O}_{2}$ saturation, $\mathrm{HR}$, and body temperature after matching the effect of time and its interactive effect with the intervention $(p>0.05)$. This test revealed a significant difference between the lavender and distilled water groups in terms of sleep quality $(p<0.001)$, such that the sleep quality was higher in the lavender group.

Conclusion: Lavender aromatherapy can increase patients' sleep quality after CABG surgery. However, it cannot completely treat sleep disorders in such patients. Furthermore, aromatherapy with lavender does not affect the physiological parameters, such as $H R, B P, R R$, and $\mathrm{O}_{2}$ saturation. Keywords: Aromatherapy, Physiological indicators, Sleep quality.

Indian Journal of Critical Care Medicine (2021): 10.5005/jp-journals-10071-23785
\end{abstract}

\section{INTRODUCTION}

According to the World Health Organization (WHO) report in 2019, cardiovascular disorders are the most common cause of mortality in the world, and about 17.9 million people die each year of such diseases worldwide. ${ }^{1}$ According to the WHO report, $43 \%$ of Iranians die of cardiovascular diseases. ${ }^{2}$ A large proportion of cardiovascular diseases are related to coronary artery diseases (CAD). People with CAD are initially treated with medication. ${ }^{3}$ However, some of these patients who do not respond to medical treatment undergo coronary artery bypass grafting (CABG). ${ }^{4}$ In Iran, CABG comprises about $60 \%$ of open-heart surgeries. ${ }^{5}$ Like other surgeries, CABG causes problems for patients including disturbances in sleep and physiological parameters. ${ }^{6,7}$

Sleep disorders occur in 60 to $80 \%$ of patients in the first days after heart surgery ${ }^{8}$ and can increase mortality, morbidity, and use of resources. ${ }^{9}$ One of the major causes of sleep disorders after CABG is anxiety and subsequent changes in physiological indicators, such as systolic blood pressure (BP), saturation of oxygen $\left(\mathrm{O}_{2}\right)$, and respiratory rate (RR) and heart rate (HR) per minute. ${ }^{7}$ Accordingly, it is important to enhance patients' sleep quality and improve physiological indicators after CABG surgery.

Interventions used to promote sleep quality and physiological indicators in patients include nonpharmacological and pharmacological methods. Currently, pharmacological methods are mostly used to treat sleep disorders and improve physiological indicators. ${ }^{10,11}$ However, sleep drugs can lead to complications, such as cognitive impairment, suppression of the respiratory
${ }^{1}$ Nursing Care Research Center, Semnan University of Medical Sciences, Semnan, Iran

${ }^{2}$ Department of Medical Emergencies, School of Medicine, Qom University of Medical Sciences, Qom, Iran; Nursing Care Research Center, Semnan University of Medical Sciences, Semnan, Iran

${ }^{3}$ Student Research Committee, Nursing School, Semnan University of Medical Sciences, Semnan, Iran

${ }^{4}$ Department of Anaesthesia, Paramedic School, Qom University of Medical Sciences, Qom, Iran

Corresponding Author: Maedeh Tourdeh, Department of Anaesthesia, Paramedic School, Qom University of Medical Sciences, Qom, Iran, Phone: +00989124981507, e-mail: tourdeh.m@gmail.com

How to cite this article: Davari H, Ebrahimian A, Rezayei S, Tourdeh M. Effect of Lavender Aromatherapy on Sleep Quality and Physiological Indicators in Patients after CABG Surgery: A Clinical Trial Study. Indian J Crit Care Med 2021;25(4):429-434.

Source of support: Nil

Conflict of interest: None

system, and the risk of tolerance and dependence. ${ }^{12}$ For example, opioids, benzodiazepines, and barbiturates disturb normal sleep rhythm and reduce stage 3 of sleep and rapid eye movement activity. ${ }^{13}$ Pharmacological treatments are more effective than nonpharmacological treatments in inducing sleep in patients. Meanwhile, nonpharmacological treatments have fewer side

( ) Jaypee Brothers Medical Publishers. 2021 Open Access This article is distributed under the terms of the Creative Commons Attribution 4.0 International License (https://creativecommons.org/licenses/by-nc/4.0/), which permits unrestricted use, distribution, and non-commercial reproduction in any medium, provided you give appropriate credit to the original author(s) and the source, provide a link to the Creative Commons license, and indicate if changes were made. The Creative Commons Public Domain Dedication waiver (http://creativecommons.org/publicdomain/zero/1.0/) applies to the data made available in this article, unless otherwise stated. 
effects. ${ }^{14}$ Accordingly, nonpharmacological treatments for improving sleep have become more important. Aromatherapy with French lavender is one of the approaches that may increase sleep quality and improve physiological parameters after CABG surgery.

Linalool acetate and linalool are the active lavender ingredient and linalool actions as a gamma-aminobutyric acid receptors sedative in the central nervous system (CNS). ${ }^{15}$ Inhaling lavender scent calms the patient and improves physiological indicators by reducing the adrenal gland cortisol secretion, reducing the activity of the sympathetic system, and increasing the activity of the parasympathetic system. Lavender inhibits acetylcholine release, and linalool acetate can relax the smooth muscles of the arteries. Furthermore, lavender calms the nervous system due to the presence of a substance called ester. ${ }^{16}$

Some studies have investigated the lavender effect on anxiety, pain, sleep, and physiological indicators in patients after cardiac surgery. ${ }^{17-21}$ However, the results are contradictory. For example, Bikmoradi et al. reported that lavender aromatherapy did not affect patients' stress and vital signs after CABG. ${ }^{21}$ Rajai showed that aromatherapy with lavender could reduce anxiety and improve physiological indicators in patients after CABG surgery. ${ }^{20}$ Therefore, because of these contradictions regarding the use of lavender to improve physiological and anxiety indicators in studies, and that the authors did not find a study that had simultaneously investigated the effect of lavender on sleep quality and physiological indicators in patients after CABG surgery, this study is aimed to determine the effect of lavender aromatherapy on patients' sleep quality and physiological indicators after CABG surgery.

\section{Materials and Methods}

\section{Study Design and Participants}

This study was a not-blinded, randomized clinical trial (ID: IRCT2017060811399N6) conducted between July 23, 2017, to March 20,2018 . The study population comprised 50 patients after CABG surgery in Kowsar Hospital Open-Heart ICU, Semnan, Iran. The study sample consisted of those patients who met the following inclusion criteria: patients' willingness to contribute in this study, nonemergency open-heart surgery, the age range of 30-75 years, stable hemodynamic conditions, no opium drug use in his/her history, no confirmed mental illness, no history of allergy to lavender aromas or any seasonal allergies, no known olfactory disorders, no known respiratory disorders, such as asthma or chronic obstructive pulmonary disease (COPD), having complete alertness, and having full hearing and speaking ability.

The exclusion criteria comprised taking sedating medications in addition to routine, life-threatening dysrhythmias, any emergency situations requiring immediate intervention, unwillingness to contribute in this study, loss of consciousness, sensitivity to lavender odor, or any allergic reaction during the study.

\section{Sample Size Estimated}

Initially, a pilot study was performed to estimate the sample size. Twenty patients were divided into two groups: lavender and distilled water. The lavender group had a sleep quality score mean and standard deviation of $25.30 \pm 5.55$, and the distilled water or control group had a sleep quality score mean and standard deviation of $30.10 \pm 5.42$. The sample size was estimated using the $\mathrm{G}^{*}$ power software with a confidence interval of $95 \%$, a test power of $90 \%$, and an effect size of 0.875 . The maximum sample size obtained was 24 patients per group.

\section{Measures}

Data collection tools were demographic and physiological parameter information and St Mary's Hospital Sleep Questionnaire (SMHSQ). The demographic and physiological parameter information of patients were complete after obtaining informed consent. This information including age, gender, underlying diseases, such as COPD, diabetes mellitus, hypertension, and hyperlipoproteinemia (HLP), level of education, history of smoking, job, weight, height, body mass index (BMI), ejection fraction, systolic $\mathrm{BP}$, body temperature, $\mathrm{O}_{2}$ saturation, and $\mathrm{HR}$ and $\mathrm{RR}$ per minute.

The SMHSQ score was used to assess patients' previous night's sleep quality. In this present study, the 11-question format of this questionnaire was used. The minimum score of this questionnaire was 11 , which was interpreted as lack of sleep quality disorder and the maximum score was 44 , demonstrating the highest amount of sleep quality disorder. This questionnaire's answers to never score 1 , very little score 2 , some extent score 3 , and a lot score 4 . Scores 11-21 showed mild sleep quality disorder, 22-32 moderate, and 33-44 severe. ${ }^{22}$ This questionnaire has validity for patients' sleep studies at the hospital and has been used in some studies. ${ }^{22,23}$ Ghorbani et al. confirmed the SMHSQ's reliability by computing a Cronbach's alpha of $0.91 .{ }^{9}$ A Cronbach's alpha of 0.87 also confirmed the reliability of the SMHSQ tool in the present study.

\section{Randomization}

After CABG surgery, eligible people were randomly divided into lavender and distilled water groups. Computerized block randomization was used to randomize.

\section{Intervention}

Eligible patients entered the study after they were fully conscious and extubated. On the first night after surgery, all patients in both groups slept with a sedative (benzodiazepine) due to severe pain. Therefore, the intervention started on the second night postop and it was not possible to record patients' sleep status and vital signs before the interventions because these variables were affected by the injected painkiller and were not valid. For three consecutive nights from the second night postop, in the intervention group two drops of lavender essence and in the control group two drops of distilled water were applied to a cotton pellet and held before the patients' nose. They were asked to take 10 effective breaths. The cotton pellet was then attached to the patients' collar where it remained until 8 a.m. the next day. These interventions were performed in both the lavender and the distilled water groups on the third and fourth nights after surgery. Patients' sleep quality was measured using SMHSQ and their vital signs were recorded in both groups at 8 a.m. the day after the interventions.

\section{Statistical Methods}

Data were analyzed using descriptive statistics, including frequency, mean and standard deviation. Chi-square test was applied to compare patients' gender, underlying diseases, marital status, history of smoking, level of education, and job. Independent t-test was applied to compare patients' mean weight, age, height, $\mathrm{BMI}$, and ejection fraction before the interventions. Independent sample $t$-test was applied to compare patients' systolic BP, body temperature, $\mathrm{O}_{2}$ saturation, $\mathrm{HR}$, and $\mathrm{RR}$ between the two groups before and after the interventions.

Independent sample $t$-test and Chi-square test were performed to compare patients' demographic data before the interventions. 
Independent sample $t$-test and repeated measurement test were performed to compare patients' mean sleep quality score and physiological parameters over 3 days of continuous measurement. Data were analyzed at a significance level of 0.05 .

\section{Ethical Considerations}

This study protocol was approved by the Ethics Committee of Semnan University of Medical Sciences (approval code: IR.SEMUMS. REC.1396.14) and registered at the Iranian Registry of Clinical Trials (registration code: IRCT2017060811399N6). All patients participating in the study provided informed consent the day after CABG surgery, and coordinated with Kowsar Hospital administrators and Open-Heart ICU nurses before sampling. The study goals and method were also clarified to the patients and informed consent was obtained.

\section{Findings}

In a total of 62 patients after CABG surgery, 57 patients were eligible to participate in this study. Seven people were excluded from this study during the sampling process because of their unwillingness to contribute to this study (one patient), loss of consciousness (one patient), taking sedating medications in addition to routine (three patients), and life-threatening dysrhythmias (two patients), and lastly, the data of 50 people were analyzed (Flowchart 1).

The participants were 15 females (30\%) and 35 males (70\%). Their mean and standard deviation age was $62.18 \pm 9.52$ years. Thirty-six patients (72\%) had primary education. Six patients (12\%) were government employees, three (6\%) were workers, eight (16\%) were retired, and 22 (44\%) were employed in other occupations. Twenty-six patients (52\%) had a history of hypertension, 13 (26\%) had diabetes, four (8\%) had COPD, and 20 (40\%) had hyperlipidemia. Fourteen patients (28\%) were active smokers. Before the intervention, patients in both groups were matched in terms of gender, age, educational level, smoking history, occupation, type of underlying disease, height, weight, BMI, and ejection fraction $(p>0.05)$ (Table 1). There was no significant difference between sleep quality scores and physiological variables before the interventions, and both groups were matched in terms of these variables $(p>0.05)$ (Table 1).

The mean and standard deviation of sleep quality scores of patients in the lavender group after the first intervention was $30.04 \pm 4.82$, the second intervention was $24.96 \pm 5.03$, and the third intervention was $25.08 \pm 4.98$. The mean and standard deviation of patients' sleep quality scores in the control group after the first intervention was $30.36 \pm 5.77$, the second intervention was $30.68 \pm 5.88$, and the third intervention was $28.44 \pm 6.62$. Independent $t$-test revealed a statistically significant difference in the sleep quality scores between the two groups on the second and third days after the intervention, such that sleep quality in the lavender group enhanced compared to the control group $(p<0.05)$. However, there was no statistically significant difference in physiological indicators between the two groups on the second and third days after the intervention ( $p>0.05$ ) (Table 2).

Repeated measures showed no significant difference between the lavender group and control group in terms of systolic BP, $\mathrm{O}_{2}$ saturation, $\mathrm{HR}$, body temperature, and RR after matching the effect of time and its interactive effect with the intervention $(p>0.05)$. However, this test revealed a significant difference between the intervention and control groups in terms of sleep quality $(p<0.001)$, such that the sleep quality was higher in the lavender group (Table 3 ).

\section{Discussion}

In this study, patients in both groups slept with the help of strong sedatives on the first night after CABG according to the ward routines; therefore, the interventions began the second night after $\mathrm{CABG}$.

The mean sleep quality scores were moderate after the first intervention in both the lavender and distilled water groups. The mean score dropped to 5.08 and 4.96 , respectively, after the

Flowchart 1: Flow of patients through the trial

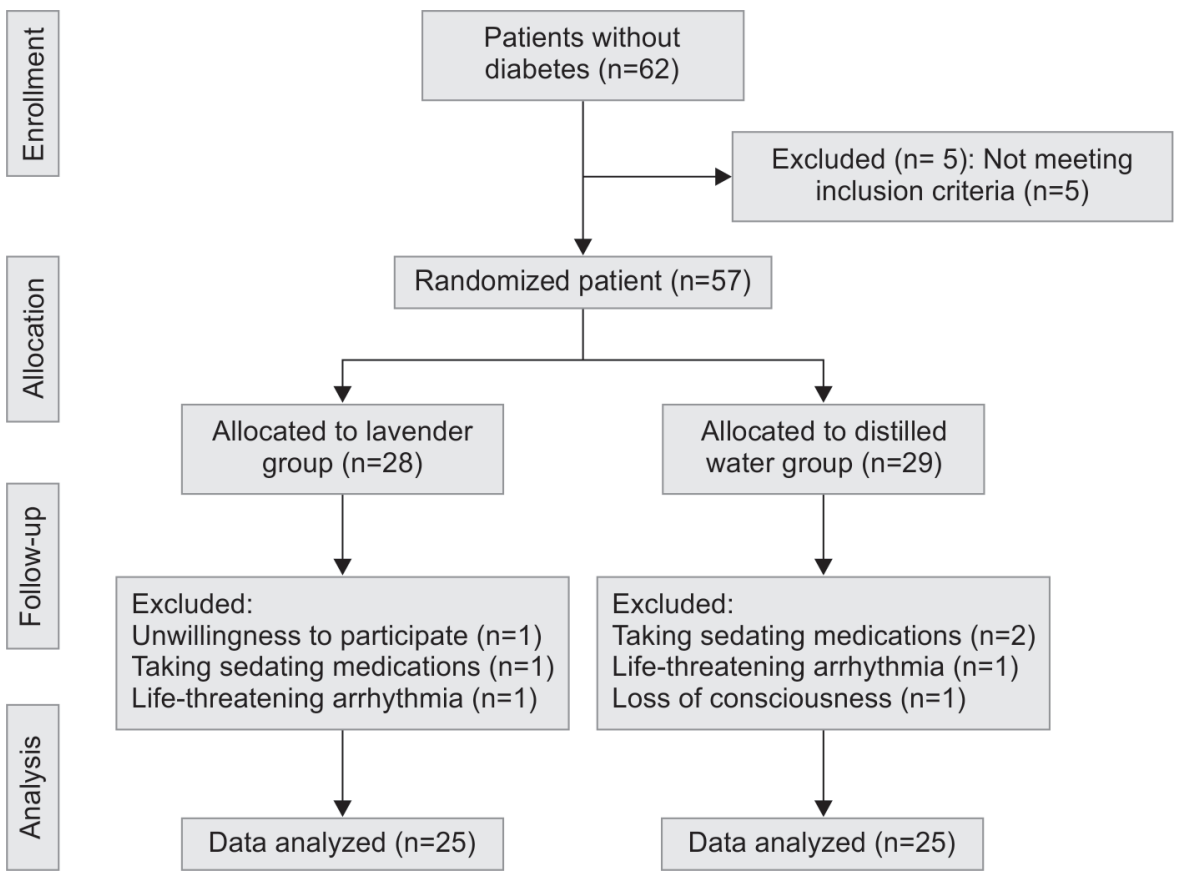


Table 1: Demographic variables and hospitalization data

\begin{tabular}{|c|c|c|c|c|}
\hline \multirow[b]{2}{*}{ Variables } & \multicolumn{3}{|c|}{ Frequency in groups } & \multirow[b]{2}{*}{ " $p$ " value } \\
\hline & Lavender & Control & Total & \\
\hline Age (year) & $62.40 \pm 9.62$ & $61.96 \pm 9.62$ & $62.18 \pm 9.52$ & $0.802 b$ \\
\hline \multicolumn{5}{|l|}{ Gender, $n(\%)$} \\
\hline Male & $16(45.7)$ & $19(54.3)$ & $35(100)$ & \multirow{2}{*}{$0.538 c$} \\
\hline Female & $9(60.0)$ & $6(40.0)$ & $15(100)$ & \\
\hline \multicolumn{5}{|l|}{ Educational level, $n(\%)$} \\
\hline Primary school & $20(55.6)$ & $16(44.4)$ & $36(100)$ & \multirow{3}{*}{$0.398 c$} \\
\hline Diploma & $4(40)$ & $6(60)$ & $10(100)$ & \\
\hline High school & $1(25)$ & $3(75)$ & $4(100)$ & \\
\hline \multicolumn{5}{|l|}{ Type of job, $n(\%)$} \\
\hline Government employees & $2(33.3)$ & $4(66.7)$ & $6(100)$ & \multirow{5}{*}{$0.405 c$} \\
\hline Proletarian & $1(33.3)$ & $2(66.7)$ & $3(100)$ & \\
\hline Unemployed & $6(54.5)$ & $5(45.5)$ & $11(100)$ & \\
\hline Retired & $6(75.0)$ & $2(25.0)$ & $8(100)$ & \\
\hline Other jobs & $10(45.5)$ & $12(54.5)$ & $22(100)$ & \\
\hline \multicolumn{5}{|l|}{ Underlying diseases, $n$ (yes, no) } \\
\hline Hypertension (yes, no) & 14,11 & 15,10 & 29,21 & $0.198 \mathrm{c}$ \\
\hline Diabetes mellitus (yes, no) & 6,19 & 7,18 & 13,37 & $0.500 c$ \\
\hline COPD (yes, no) & 2,23 & 2,23 & 4,46 & $0.695 c$ \\
\hline HLP (yes, no) & 8,17 & 12,13 & 20,30 & $0.193 c$ \\
\hline \multicolumn{5}{|l|}{ Habit of smoking, $n$ (\%) } \\
\hline Yes & $6(42.9)$ & $8(57.1)$ & $14(100)$ & \multirow{2}{*}{$0.377 c$} \\
\hline No & $19(52.8)$ & $17(47.2)$ & $36(100)$ & \\
\hline Weight (kg) & $72.96 \pm 11.27$ & $74.56 \pm 9.06$ & $73.76 \pm 10.15$ & $0.583 c$ \\
\hline Height $(\mathrm{cm})$ & $166.32 \pm 6.38$ & $169.04 \pm 7.60$ & $167.68 \pm 7.08$ & $0.177 c$ \\
\hline BMI & $26.32 \pm 3.87$ & $26.12 \pm 3.21$ & $26.24 \pm 3.52$ & $0.843 c$ \\
\hline Ejection fraction & $47.80 \pm 8.04$ & $47.60 \pm 6.63$ & $47.70 \pm 7.29$ & $0.924 c$ \\
\hline
\end{tabular}

Data are presented as $n(\%)$, yes/no, or mean \pm SD. SD, standard deviation; $b$, independent sample $t$-test; c, Chi-square test

second and third interventions in the lavender group. However, the mean score increased by 0.32 after the second intervention and decreased by 1.92 after the third intervention in the control group. Statistical tests also showed that the mean sleep quality scores were not significantly different between the two groups after the first intervention, but the difference became significant after the second and third interventions. Cheraghbeigi et al. reported that lavender can increase sleep quality in people with heart diseases. ${ }^{24}$ Moeini et al. reported that inhaling lavender can increase sleep quality in patients with ischemic heart disease. In their study, the mean sleep quality score decreased by 6.42 after inhaling lavender reaching from 20.12 to $13.97 .^{22}$

In a study, Babamohamadi et al. showed that aromatherapy could increase patients' sleep quality after heart surgery. ${ }^{25}$ Ghorbani et al. also showed that complementary medicine could increase patients' sleep quality after CABG surgery. ${ }^{9}$ Lavender appears to increase patients' sleep quality after CABG by reducing stress and anxiety. ${ }^{26}$ However, this hypothesis needs further studies. The findings of our study and other studies on the effect of complementary medicine and aromatherapy on patients' sleep quality after heart surgery showed that aromatherapy with lavender and other complementary therapies significantly increased patients' sleep quality, but they could not completely alleviate patients' sleep problems. Therefore, it is recommended that further studies be conducted using other complementary therapies. The combined use of complementary medicine and conventional medications may further treat the problem of patients' sleep disorders after heart surgery.

The present study showed that lavender inhalation did not have a significant effect on patients' physiological parameters after CABG surgery. To confirm this finding, Bikmoradi et al. showed that lavender aromatherapy did not affect patients' vital signs after CABG. ${ }^{21}$ However, Abdelhakim et al. showed that lavender could reduce $H R$ in patients after heart surgery, but it did not affect their BP. ${ }^{27}$ Ebrahimi Hossein Abadi et al. reported that lavender aromatherapy could only affect patients' BP after CABG and had no effect on other physiological parameters. ${ }^{28}$ In a study, Rajai et al. showed that lavender aromatherapy could improve physiological indicators in patients after $\mathrm{CABG} .{ }^{20} \mathrm{~A}$ comparison of the results of our study with other similar studies reveals the contradictory effect of lavender aromatherapy on physiological parameters after CABG. Different administration methods, administration times, research settings, and demographic characteristics of the participants in different studies appear to cause these contradictions. Therefore, more studies are needed to show the exact lavender effect on physiological parameters after CABG surgery. 
Table 2: Comparison of mean patients' physiological parameters and SMHSQ score before and after interventions in the two groups studied

\begin{tabular}{|c|c|c|c|c|}
\hline $\begin{array}{l}\text { Physiological } \\
\text { parameters }\end{array}$ & Times & $\begin{array}{l}\text { Lavender } \\
M \pm S D\end{array}$ & $\begin{array}{l}\text { Control } \\
M \pm S D\end{array}$ & $\begin{array}{l}\text { "p" } \\
\text { value }\end{array}$ \\
\hline \multirow{3}{*}{$\begin{array}{l}\text { Systolic } \\
\text { blood } \\
\text { pressure }\end{array}$} & $\begin{array}{l}1 \text { day after } \\
\text { intervention }\end{array}$ & $115.48 \pm 19.08$ & $110.72 \pm 19.54$ & 0.388 \\
\hline & $\begin{array}{l}2 \text { days after } \\
\text { intervention }\end{array}$ & $111.52 \pm 20.95$ & $109.36 \pm 21.75$ & 0.722 \\
\hline & $\begin{array}{l}3 \text { days after } \\
\text { intervention }\end{array}$ & $114.96 \pm 20.39$ & $121.76 \pm 19.40$ & 0.233 \\
\hline \multirow[t]{3}{*}{ Heart rate } & $\begin{array}{l}1 \text { day after } \\
\text { intervention }\end{array}$ & $93.88 \pm 12.72$ & $94.84 \pm 16.72$ & 0.820 \\
\hline & $\begin{array}{l}2 \text { days after } \\
\text { intervention }\end{array}$ & $90.48 \pm 12.71$ & $92.80 \pm 12.04$ & 0.511 \\
\hline & $\begin{array}{l}3 \text { days after } \\
\text { intervention }\end{array}$ & $91.56 \pm 11.55$ & $90.52 \pm 13.82$ & 0.774 \\
\hline \multirow[t]{3}{*}{$\begin{array}{l}\text { Respiratory } \\
\text { rate }\end{array}$} & $\begin{array}{l}1 \text { day after } \\
\text { intervention }\end{array}$ & $13.28 \pm 2.45$ & $14.08 \pm 2.15$ & 0.227 \\
\hline & $\begin{array}{l}2 \text { days after } \\
\text { intervention }\end{array}$ & $13.24 \pm 2.55$ & $13.20 \pm 2.81$ & 0.958 \\
\hline & $\begin{array}{l}3 \text { days after } \\
\text { intervention }\end{array}$ & $12.72 \pm 3.23$ & $12.48 \pm 3.21$ & 0.794 \\
\hline \multirow[t]{3}{*}{ Temperature } & $\begin{array}{l}1 \text { day after } \\
\text { intervention }\end{array}$ & $36.79 \pm 0.37$ & $36.92 \pm 0.42$ & 0.283 \\
\hline & $\begin{array}{l}2 \text { days after } \\
\text { intervention }\end{array}$ & $36.99 \pm 0.17$ & $37.06 \pm 0.41$ & 0.451 \\
\hline & $\begin{array}{l}3 \text { days after } \\
\text { intervention }\end{array}$ & $36.90 \pm 0.28$ & $36.92 \pm 0.31$ & 0.853 \\
\hline \multirow[t]{3}{*}{$\begin{array}{l}\mathrm{O}_{2} \\
\text { saturation }\end{array}$} & $\begin{array}{l}1 \text { day after } \\
\text { intervention }\end{array}$ & $97.32 \pm 1.60$ & $97.64 \pm 1.80$ & 0.510 \\
\hline & $\begin{array}{l}2 \text { days after } \\
\text { intervention }\end{array}$ & $92.96 \pm 2.35$ & $94.44 \pm 2.88$ & 0.053 \\
\hline & $\begin{array}{l}3 \text { days after } \\
\text { intervention }\end{array}$ & $93.00 \pm 2.94$ & $92.96 \pm 3.48$ & 0.965 \\
\hline \multirow[t]{3}{*}{$\begin{array}{l}\text { SMHSQ } \\
\text { score }\end{array}$} & $\begin{array}{l}1 \text { day after } \\
\text { intervention }\end{array}$ & $30.04 \pm 4.82$ & $30.36 \pm 5.77$ & 0.833 \\
\hline & $\begin{array}{l}2 \text { days after } \\
\text { intervention }\end{array}$ & $24.96 \pm 5.03$ & $30.68 \pm 5.88$ & $0.001^{*}$ \\
\hline & $\begin{array}{l}3 \text { days after } \\
\text { intervention }\end{array}$ & $25.08 \pm 4.98$ & $28.44 \pm 6.62$ & $0.048^{*}$ \\
\hline
\end{tabular}

An independent sample $t$-test

Table 3: Results of analysis of variance with observation repetition approach

\begin{tabular}{lcllll}
\hline Factors & Sum of squares & $d f$ & Mean square & $F$ & Sig. \\
\hline $\begin{array}{l}\text { Systolic blood } \\
\text { pressure }\end{array}$ & 919.480 & 2 & 459.740 & 1.03 & 0.361 \\
Heart rate & 71.413 & 2 & 35.707 & 0.254 & 0.776 \\
Respiratory rate & 0.073 & 2 & 0.036 & 0.345 & 0.709 \\
Temperature & 7.613 & 2 & 3.807 & 0.473 & 0.624 \\
$\mathrm{O}_{2}$ saturation & 15.773 & 2 & 7.887 & 1.244 & 0.293 \\
SMHSQ score & 183.213 & 2 & 91.607 & 4.879 & $0.010^{*}$ \\
\hline
\end{tabular}

*There was a significant difference between the intervention groups and the sleep quality was higher in the lavender group.

\section{CONCLUSION}

Aromatherapy with lavender can improve sleep quality in patients undergoing $C A B G$. However, it cannot completely treat sleep disorders in such patients. Furthermore, lavender aromatherapy does not affect physiological parameters, such as $\mathrm{HR}, \mathrm{BP}, \mathrm{RR}$, and $\mathrm{O}_{2}$ saturation. Therefore, it is suggested that lavender aromatherapy be used as a complementary measure to conventional medications to increase sleep quality in patients after CABG surgery.

\section{ACKnOWLedgments}

Authors would like to thank the Nursing Care Research Center and Clinical Research Development Unit of Kowsar Educational Research and Therapeutic Center of Semnan University of Medical Sciences for providing facilities for this work, and all patients that participated in this study and their sincere cooperation. This study was supported financially by Semnan University of Medical Sciences (grant no: 1215).

\section{Author Contributions}

$A E, M T$, and $H D$ conceived and designed the study. AE devised and developed the project and wrote the first draft of the manuscript. HD developed data collection. AE and MT were involved in data management and analysis and edited the manuscript. $\mathrm{AE}$ supervised the conduct of the study and data collection. All authors contributed to the review and revision of the manuscript and all took responsibility for the final version. All authors read and approved the manuscript.

\section{Ethical Considerations}

This study protocol was approved by the Ethics Committee of Semnan University of Medical Sciences (approval code: IR.SEMUMS. REC.1396.14) and registered at the Iranian Registry of Clinical Trials (registration code: IRCT2017060811399N6).

\section{OrCID}

Hossein Davari (1) https://orcid.org/0000-0002-5604-7049 Abbasali Ebrahimian @ https://orcid.org/0000-0003-2665-0514

Soraya Rezayei (i) https://orcid.org/0000-0001-9952-2498 Maedeh Tourdeh @ https://orcid.org/0000-0003-2554-3020

\section{References}

1. https://www.who.int/health-topics/cardiovascular-diseases/ \#tab=tab_1.

2. https://www.who.int/nmh/countries/irn_en.pdf?ua=1.

3. Hinkle JL, Cheever KH. Brunner \& Suddarth's textbook of medicalsurgical nursing. 14th ed. Wolters Kluwer; 2018.

4. Williams MA. American Association of Cardiovascular and Pulmonary Rehabilitation guideline for cardiac rehabilitation and secondary prevention programs. 4th ed. Human Kinetics; 2004.

5. Babaee GKM, Heidarnia A. Evaluation of quality of life in patients with coronary artery bypass surgery using controlled clinical trial. Acta Med Iran 2007;45(1):69-75.

6. Choudhury M, Gupta A, Hote MP, Kapoor PM, Khanna S, Kalaivani $M V$, et al. Does sleep quality affects the immediate clinical outcome in patients undergoing coronary artery bypass grafting: a clinicobiochemical correlation. Ann Card Anaesth 2017;20(2):193-199. DOI: 10.4103/aca.ACA_30_17.

7. Abbaszadeh Y, Allahbakhshian A, Seyyedrasooli A, Sarbakhsh P, Goljarian S, Safaei N. Effects of foot reflexology on anxiety and physiological parameters in patients undergoing coronary artery bypass graft surgery: a clinical trial. Complement Ther Clin Pract 2018;31:220-228. DOI: 10.1016/j.ctcp.2018.02.018.

8. Greve H, Pedersen PU. Improving sleep after open-heart surgery: effectiveness of nursing interventions. J Nurs Educ Pract 2016;6:15-25. DOI: 10.5430/jnep.v6n3p15. 
9. Ghorbani A, Hajizadeh F, Sheykhi MR, Poor Asl AM. The effects of deepbreathing exercises on postoperative sleep duration and quality in patients undergoing coronary artery bypass graft (CABG): a randomized clinical trial. J Caring Sci 2018;8(4):219-224. DOI: 10.15171/jcs.2019.031.

10. Abad VC, Guilleminault C. Pharmacological treatment of sleep disorders and its relationship with neuroplasticity. Curr Top Behav Neurosci 2015;25:503-553. DOI: 10.1007/7854_2014_365.

11. Sowparnika GC, Thirumarimurugan M, Sivakumar VM, Vinoth $N$. Controlled infusion of intravenous cardiac drugs using global optimization. Indian J Pharmacol 2019;51(1):61-71. DOI: 10.4103/ijp. IJP_612_18.

12. Mistraletti G, Carloni E, Cigada M, Zambrelli E, Taverna M, Sabbatici G, et al. Sleep and delirium in the intensive care unit. Minerva Anestesiol 2008;74(6):329-333. PMID: 18500209.

13. Cronin AJ, Keifer JC, Davies MF, King TS, Bixler EO. Postoperative sleep disturbance: influences of opioids and pain in humans. Sleep Med Clin 2001;24(1):39-44. DOI: 10.1093/sleep/24.1.39.

14. Jacobi J, Fraser GL, Coursin DB, Riker RR, Fontaine D, Wittbrodt ET, et al. Clinical practice guidelines for the sustained use of sedatives and analgesics in the critically ill adult. Crit Care Med 2002;30(1):119-141. DOI: 10.1097/00003246-200201000-00020.

15. Perry R, Terry R, Watson LK, Ernst E. Is lavender an anxiolytic drug? A systematic review of randomised clinical trials. Phytomedicine 2012;19(8-9):825-835. DOI: 10.1016/j.phymed.2012.02.013.

16. Lytle J, Mwatha C, Davis KK. Effect of lavender aromatherapy on vital signs and perceived quality of sleep in the intermediate care unit: a pilot study. Am J Crit Care 2014;23(1):24-29. DOI: 10.4037/ajcc2014958.

17. Hasanzadeh F, Kashouk NM, Amini S, Asili J, Emami SA, Vashani HB, et al. The effect of cold application and lavender oil inhalation in cardiac surgery patients undergoing chest tube removal. EXCLI J. 2016;15:64-74. DOI: 10.17179/excli2015-748.

18. Hassanzadeh M, Sajadi SA, Farsi Z. Comparison effect of Sedamin capsule and inhaling Lavender essence on sleep quality of hospitalized patients in cardiac care unit. Mil Caring Sci 2018;4(3):187197. DOI: 10.29252/mcs.4.3.187.

19. Salamati A, Mashouf S, Mojab F. Effect of inhalation of lavender essential oil on vital signs in open heart surgery ICU. Iran J Pharm Res 2017;16(1):404-409. PMID: 28496494. PMCID: PMC5423266.

20. Rajai N, Sajadi SA, Teymouri F, Zareiyan A, Siavoshi S, Malmir M. The effect of aromatherapy with lavender essential oil on anxiety and stress in patients undergoing coronary artery bypass graft surgery. Jundishapur J Chronic Dis Care 2016;5(4):e34035. DOI: 10.17795/jjcdc34035.

21. Bikmoradi A, Seifi Z, Poorolajal J, Araghchian M, Safiaryan R, Oshvandi K. Effect of inhalation aromatherapy with lavender essential oil on stress and vital signs in patients undergoing coronary artery bypass surgery: a single-blinded randomized clinical trial. Complement Ther Med 2015;23(3):331-338. DOI: 10.1016/j.ctim.2014.12.001.

22. Moeini M, Khadibi M, Bekhradi R, Mahmoudian SA, Nazari F. Effect of aromatherapy on the quality of sleep in ischemic heart disease patients hospitalized in intensive care units of heart hospitals of the Isfahan university of medical sciences. Iran J Nurs Midwifery Res 2010;12(4):234. PMCID: PMC3203283. PMID: 22049287.

23. Pien GW, Sammel MD, Freeman EW, Lin H, DeBlasis TL. Predictors of sleep quality in women in the menopausal transition. Sleep 2008;31(7):991-999. PMID: 18652094. PMCID: PMC2491505.

24. Cheraghbeigi N, Modarresi M, Rezaei M, Khatony A. Comparing the effects of massage and aromatherapy massage with lavender oil on sleep quality of cardiac patients: A randomized controlled trial. Complement Ther Clin Pract 2019;35:253-258. DOI: 10.1016/j. ctcp.2019.03.005.

25. Asgari MR, Vafaei-Moghadam A, Babamohamadi H, Ghorbani R, Esmaeili R. Comparing acupressure with aromatherapy using Citrus aurantium in terms of their effectiveness in sleep quality in patients undergoing percutaneous coronary interventions: a randomized clinical trial. Complement Ther Clin Pract 2020;38:101066. DOI: 10.1016/j.ctcp.2019.101066.

26. Donelli D, Antonelli M, Bellinazzi C, Gensini GF, Firenzuoli F. Effects of lavender on anxiety: a systematic review and meta-analysis. Phytomedicine 2019;65:153099. DOI: 10.1016/j.phymed.2019.153099.

27. Abdelhakim AM, Hussein AS, Doheim MF, Sayed AK. The effect of inhalation aromatherapy in patients undergoing cardiac surgery: a systematic review and meta-analysis of randomized controlled trials. Complement Ther Med 2020;48:102256. DOI: 10.1016/j. ctim.2019.102256.

28. Ebrahimi Hosein Abadi S, Paryad E, Ghanbari Khanghah A, Pasdaran A, Kazem Nezhad Leyli E, Sadeghi Meibodi AM. Effects of aromatherapy using lavender oil on hemodynamic indices after coronary artery bypass graft surgery. J Holist Nurs Midwifery 2018;28(3):163-170. DOI: 10.29252/hnmj.28.3.163. 